\title{
ULTIMATE STRENGTH ANALYSIS OF RC DEEP BEAMS USING STRUT-AND-TIE MODELS
}

\author{
Daeyon WON ${ }^{1}$, Shin-ichi HINO ${ }^{2}$ and Toshiaki OHTA ${ }^{3}$ \\ ${ }^{1}$ Member of ISCE, M. Eng., Graduate Student, Dept. of Civil Eng., Kyushu University \\ (10-1, Hakozaki 6, Higashi-ku, Fukuoka 812-8581, Japan) \\ ${ }^{2}$ Member of JSCE, Dr. Eng., Associate Professor, Dept. of Civil Eng., Kyushu University \\ (10-1, Hakozaki 6, Higashi-ku, Fukuoka 812-8581, Japan) \\ ${ }^{3}$ Member of JSCE, Dr. Eng., Professor, Dept. of Civil Eng., Kyushu University \\ (10-1, Hakozaki 6, Higashi-ku, Fukuoka 812-8581, Japan)
}

\begin{abstract}
Strut-and-tie models for simply supported deep beams with or without web reinforcement are proposed. The ultimate capacity of deep beams is very sensitive to the manner of modeling nodal zones and selecting an appropriate effective compressive strength. In this study, the new effective compressive strength and nodal models for the detailing of the CCT -nodes are also presented.

The validity of the proposed model is examined by comparison with experimental results in many other works which yielded most of information on behavior of deep beams published to date, and good agreement between measured and predicted values by the proposed models is obtained.
\end{abstract}

Key Words: strut-and-tie-model, deep beam, effective compressive strength, CCT-nodes, stirrups

\section{INTRODUCTION}

Up to now, many investigators ${ }^{1,2), 3), 4)}$ have studied the structural behavior of deep beams and also suggested a few of approximate design equations for predicting ultimate shear strength of $\mathrm{RC}$ deep beams. These equations, however, give excellent correlation with only known experimental results, but often fail to predict the ultimate strengths when the geometrical parameters of the beams are different from its considerations. To maintain the same accuracy over a wide range of parameters, the design method must be based on a rational theory, which can provide a clearer structural behavior and a simplified approach to a complex problem.

The formulas in Clause 13.2.7 of JSCE code ${ }^{5)}$ is based on the analytical results of non-linear FEM and gives good predictions of shear strength for the simply supported deep beams. However, the design equation cannot reflect the effect of shear reinforcement.

Strut-and-tie models or truss models are considered to be the rational and appropriate basis for design and ultimate strength analysis of cracked reinforced concrete beams, because they give a clear picture of the behavior of structural concrete.

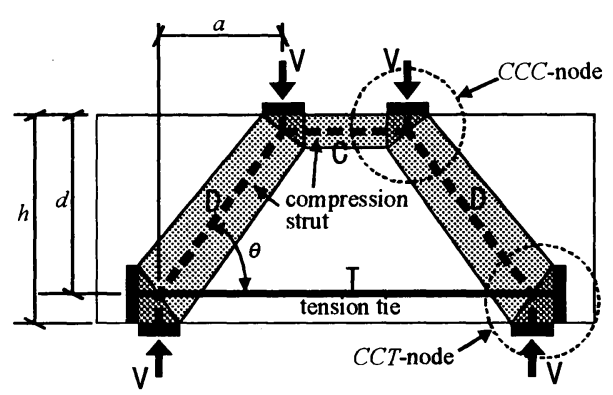

Fig.1 Typical strut-and-tie model for deep beams ${ }^{7)}$

In strut-and-tie models the flow of forces in a structure is approximated by a system of compression members, the struts, and tension members, the ties, which intersect at nodes (see Fig.1). The forces in the members are determined from equilibrium conditions and then can be used to evaluate compressive stresses in the concrete and to proportion the reinforcement. And a node as introduced into model implies an abrupt change of direction of the forces. There are essentially four types of nodes depending on the combination of struts $C$ and ties $T$, i.e. $C C C$-node, $C C T$-node, $C T T$ node, TTT-node ${ }^{6}$. 
The strut-and-tie model for the simply supported deep beams was developed by Collins and Mitchell ${ }^{11}$ and was adopted by the CSA Concrete code [A23.394] ${ }^{8)}$. The CEB-FIP Model code $1990{ }^{9)}$ also adopted strut-tie-models as the design tools to design deep beams. The basic procedure of structural idealization for deep beams is quite same in both codes, but the design criteria for effective compressive strength for concrete struts is different.

In this paper, strut-and-tie models for simply supported RC deep beams with or without shear reinforcement are proposed, and the new effective compressive strength and nodal models for the detailing of the $C C T$-node are also presented. The validity of the proposed model is compared with previously published experimental data on the behavior of deep beams. And its accuracy is also verified by comparisons with Niwa's equation ${ }^{10 !}$. the CEB-FIP Model code 1990, and the CSA Concrete code [A23.3-94].

\section{EFFECTIVE COMPRESSIVE STRENGTH}

The physical basis of strut-and-tie models is back to the lower bound theorem of plasticity. However plain concrete will not show a perfectly plastic behavior, because of the failing branch of its stressstrain curve and the limited ultimate strain (see Fig.2). The slope of the descending part strongly depends on the strength of concrete $f_{c k}$, where $f_{c k}$ is the compressive strength obtained in the cylinder test; as the strength of concrete becomes greater, the slope of failing branch becomes steeper, as shown in Fig.3. But even if the concrete strength has a stronger influence on the limit load, a good correlation with test results can be achieved, when a reduced "effective compressive strength $f_{c e}$ " is taken into account ${ }^{11}$.

The CEB-FIP Model code limits the stress of concrete in compression as follows:

$$
f_{c e l}=0.85\left(1-\frac{f_{c k}}{250}\right) f_{c k}
$$

for uncracked zones and nodes where only compression struts meet, or as

$$
f_{c c 2}=0.60\left(1-\frac{f_{c k}}{250}\right) f_{c k}
$$

for cracked zones and nodes where the compressive resistance may be reduced by the effect of transverse tension from reinforcement and by the need to transmit force across the cracks. But, $f_{\text {cel }}$ may also be applied in other nodes if the angle between ties and major struts is

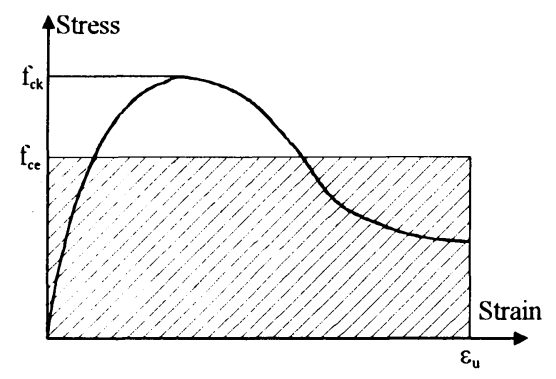

Fig.2 Effective compressive strength of concrete

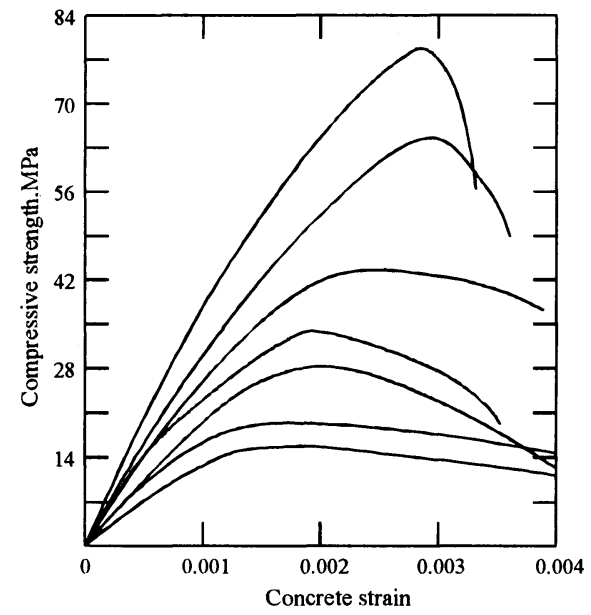

Fig.3 Stress-strain curves for concrete ${ }^{13)}$

not less than $55^{\circ}$ and if the reinforcement layout in the node region is specially designed (e.g. arranged in several layers, with transverse ties).

It has been proposed in the CSA Concrete code that the value for $f_{c e}$ shall be computed from

$$
f_{c e}=\frac{f_{c k}}{0.8+170 \varepsilon_{1}} \leq 0.85 f_{c k} \quad[\mathrm{MPa}](3)
$$

and $\varepsilon_{1}$ is calculated as

$$
\varepsilon_{1}=\varepsilon_{s}+\left(\varepsilon_{s}+0.002\right) \cot ^{2} \theta
$$

and $\theta$ is the smallest angle between the compressive strut and the adjoining tension ties and $\varepsilon_{s}$ is the tension strain in the tension tie inclined at $\theta$ to the compressive strut. This strain softening concept for determining the effective compressive strength of struts was developed by Collins et al. ${ }^{7)}$ and Vecchio et al. ${ }^{12)}$. The CSA Concrete code limits the stress of concrete in nodal regions as follows: (a) $0.85 f_{c k}$ in nodal zones bounded by compressive struts and bearing areas; (b) $0.75 f_{c k}$ in nodal zones anchoring only one tension tie; and (c) $0.60 f_{c k}$ in nodal zones 
anchoring tension ties in more than one direction. But the code also provides a special requirement that the beneficial effect of confinement may be accounted for if substantiated by the test results.

Nielsen et al. ${ }^{14)}$ carried out an extensive experimental test program in order to determine the effective compressive strength in the web, and proposed that for practical purposes the effective compressive strength can be considered to be a function of $f_{c k}$ only for beams with ordinary or prestressed reinforcement and vertical stirrups as follows:

$$
f_{c e}=\left(0.8-\frac{f_{c k}}{200}\right) f_{c k}
$$

But, Nielsen also observed that for beams without shear reinforcement the effective compressive strength of concrete is strongly dependent on the shear span-to-depth ratio, a/h or a/d. Smaller $a / h$ values give substantially higher effective compressive strength than greater $a / h$ values. The reason for this is due to the fact that for small $a / h$ values the beam acts very much as an arch already in the uncracked elastic region, while for greater values of $a / h$ a considerable redistribution of stresses occurs before the final collapse. Wang et al. ${ }^{15)}$ argued that the shear span/depth ratio should be taken into account for determining the $f_{c e}$ values of struts for deep beams when $a / h$ to be less than 2.0 because the stress state in the shear span is not uniaxial stress state. According to the statistical analysis for the deep beams, Wang et al. proposed the effective compressive strength as follows:

$$
f_{c e}=\left(0.8-\frac{f_{c k}}{200}\right)\left(1.25-0.25 \frac{a}{h}\right) f_{c k}
$$

For a deep beam subjected to shear loading, the lateral confining pressure occurs in the concrete within shear span. The lateral confining pressure leads to increase in strength as well as an increase in ductility. When the shear-span ratio is smaller, the lateral confining pressure is greater.

For the stress fields developed in strut-and-tie models the stress states in concrete were often superimposed by a strain state imposed by the elongation of the tensile reinforcement. The deformation of the reinforcement produces cracking in concrete. Thus there results a strain softening and a decrease in compressive strength. For this reason the disturbance from reinforcing bar should also be considered when $f_{c e}$ is determined.

Determining the effective compressive strength for struts and nodes depends largely on engineering judgment or on test results. In this paper, the authors proposed new effective compressive strengths for the inclined struts and CCT nodal zones. The proposed equations take into account the following parameters: concrete strength, shear-span ratio, and the disturbance from reinforcing bars. When the beams contained the equal amount of main reinforcement correspondence to the required tensile force to proportion the force of the inclined concrete strut from equilibrium conditions at the $C C T$-node, the effective compressive strength will be determined by:

$$
f_{c e 2}^{i}=0.68\left(1-\frac{f_{c k}}{250}\right)\left(1.25-0.25 \frac{a}{d}\right) f_{c k}[\mathrm{MPa}](7)
$$

When the provided main reinforcements are greater than the required tensile reinforcements, the disturbance from reinforcing bars may be decreased because of the reduction of the stress in the tensile tie. In this case, the effective compressive strength also be increased, and can be proposed as

$$
f_{c e 2}=\frac{\left(1-f_{c k} / 250\right)(1.25-0.25 a / d)}{0.5+\sqrt{T_{a} / T_{\max }}} f_{c k}[\mathrm{MPa}](8)
$$

where $T_{a}$ is the required force in tension tie using Eq.(7); $T_{\max }$ is the maximum force in tension tie provided, $A_{s} f_{y} ; A_{s}$ is the provided area of tension tie; $f_{y}$ is the yield stress of tension tie.

If $T_{\max }=T_{a}$, both of Eq.(7) and (8) will provide the approximately same results.

In this study, the effective compressive strength of the concrete struts bearing on the $C C C$-node is calculated according to the criteria of the CEB-FIP Model code; Eq.(1) is applied to the node surface which is bound to the inclined struts, and the criteria of biaxial compression strength $f_{2 c k}$, is applied to the node surface which is bound to the compression chords of beams.

$$
f_{2 c k}=\frac{1+3.80 \alpha}{(1+\alpha)^{2}} f_{c k}
$$

where $\quad \alpha=\frac{\min \left(\sigma_{b}, \sigma_{c 2}\right)}{\max \left(\sigma_{b}, \sigma_{c 2}\right)}$

and $\sigma_{b}$ is the bearing stress under concentrated load; $\sigma_{c 2}$ is the stress in the section orthogonal to the bearing.

\section{DETAILING NODES}

The nodes of the strut-and-tie model are a simplified idealization of reality, and usually form two-dimensional stress fields. According to the 
stress states within the interior of the nodes, the nodes will be treated as "hydrostatic or nonhydrostatic". If the stress fields bearing on the nodes have equal stress intensity and intersect to each sides of the nodes by perpendicular, the stress state inside of the nodes is homogeneous and a so-called "pseudo-hydrostatic". In this case, the size of the nodal area is only limited by the existing boundary of the bearing plate. In a "non-hydrostatic" stress state, the stress fields bearing on the nodes have not equal stress intensity and not intersect to the nodes by perpendicular, then a non-homogeneous stress state will generally exist. The stress state in this zone can be found by the Mohr's circles ${ }^{16)}$

\section{(1) The $C C C$-node}

The $C C C$-node will occur under the concentrated loads. The node regions are assumed to be a plane non-hydrostatic as shown in Fig.4. Also, the stress fields along each sides of the node are assumed to be a uniformly distributed. The effective widths of the inclined struts are influenced by the length of the bearing plates $r_{t}$, and the depth of the top horizontal compression struts $d_{a}$.

In this study, the pressure $\sigma_{c l}$ along the inclined face of the node will be checked with respect to $f_{c e l}$ and the pressure $\sigma_{c 2}$ in the section orthogonal to the bearing will be verified with respect to $f_{2 c k}$. However, the bearing stress $\sigma_{b}$ was not checked, because many of experimental results had shown that the bearing stresses of the beams which failed in shear or web crushing modes were greater than the biaxial compressive strength of concrete, especially when the size of bearing plates were very small in comparison with the depth of beams or the concrete was confined by means of lateral reinforcement.

For a given $d_{a}$ value, the effective width of inclined concrete strut $w_{\text {eff }}^{t}$ can be determined by:

where

$$
w_{\text {eff }}^{t}=r_{t} \sin \theta+d_{a} \cos \theta
$$

$$
\theta=\tan ^{-1}\left(\frac{d-0.5 d_{a}}{a}\right)
$$

Hence, the compressive force of $D_{t}$ in the inclined concrete strut can be found by:

$$
D_{t}=b f_{c e l} w_{e t f}^{t}
$$

or

$$
D_{t}=b f_{c e l}\left(r_{t} \sin \theta+d_{a} \cos \theta\right)
$$

\section{(2) The CCT-node}

These types of nodes occur at end-supports of deep beams. Detailing of the CCT nodal zone is
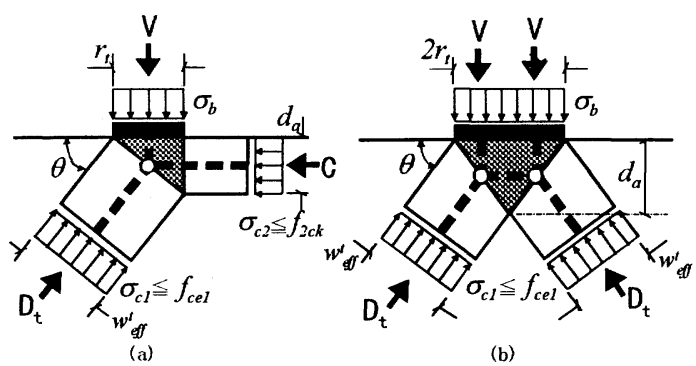

(b)

Fig.4 The $C C C$-node: (a) node under two point loads; (b) node under concentrated load

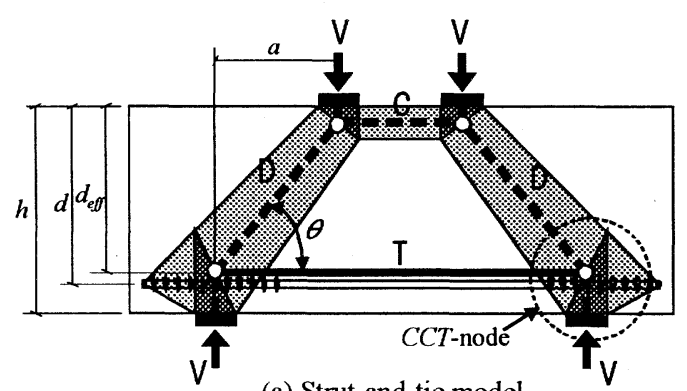

(a) Strut-and-tie model
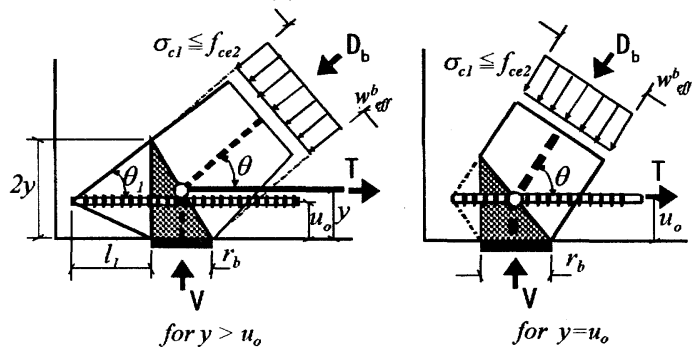

(b) detail of the CCT-nodes

Fig.5 Proposed models for the beam without stirrups (Non-hydrostatic nodes)

closely related to the following parameters as the type of anchorage for reinforcing bars, the state of stress within the interior of the nodes, the size of bearing plates, the anchorage length, and the location of tension ties. The CCT-nodes that will reflect the previous parameters are proposed by the authors in this study (see Fig.5 and Fig.6). Among the proposed models for the CCT -node, more than one model can be applied to the same beam for calculating its ultimate capacity. The ultimate capacity of the beam will vary with the types of node models. The type of node model which will gives the greater capacity depends generally on the geometrical parameters of the beams.

\section{a) Non-hydrostatic nodal model}

From the equilibrium conditions at the nodal zone as shown in Fig.5(b), the relationship between the resultant forces can be derived: 


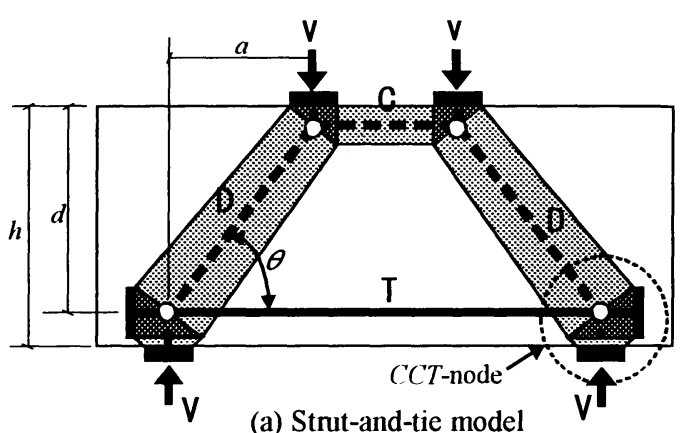

(a) Strut-and-tie model

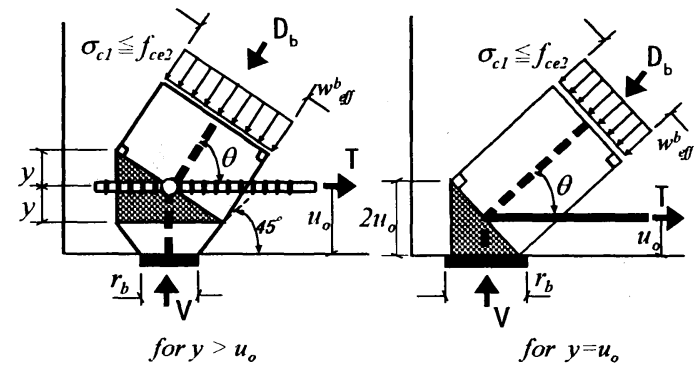

(b) detail of the CCT-nodes

Fig.6 Proposed models for the beam without stirrups

(Hydrostatic nodes)

$$
\begin{gathered}
T=D_{b} \cos \theta \\
V=D_{b} \sin \theta
\end{gathered}
$$

where

$$
D_{b}=b f_{c e 2} w_{e f f}^{b}
$$

The effective width of concrete strut $\mathrm{w}^{b}$ eff in nonhydrostatic nodal models will vary with the anchorage lengths of tension reinforcements $l_{l}$, computed from behind the bearing plates (see Fig.5) For a given value of $l_{l}$, the following relationship between $w^{b}{ }_{\text {eff }}$ and $l_{l}$ can be derived:

$$
w_{\text {eff }}^{b}=r_{b} \sin \theta+2 y \cos \theta
$$

where

$$
\begin{aligned}
& y=\left(l_{1} \tan \theta_{1}+u_{o}\right) / 2 \\
& \theta=\tan ^{-1}\left(\frac{d_{e f f}-0.5 d_{a}}{a}\right) \\
& \theta_{1}=\tan ^{-1}\left(\frac{d}{a+l_{1}+0.5\left(r_{b}-r_{t}\right)}\right) \\
& d_{e f f}=h-y \leq d
\end{aligned}
$$

From Eq.(18) and (19), it can be seen that as the anchorage length becomes longer, the effective width of concrete strut will be increased, but the strut angle $\theta$ will be decreased. And, as can be seen from Eq.(16), the ultimate capacity of the beam $V$, is related to both $D_{b}$ and $\theta$, then the value of $l_{l}$ which yields the maximum value of the ultimate capacity of the beam may be determined by iterating procedure. However, the anchorage length should be less than or equal to the result of subtracting $r_{b}$ from $l_{d}$, where $l_{d}$ is the development length of the straight reinforcement in tension given in the code. Further, Eq.(19) is only valid when the depth $d_{\text {eff }}$ is not greater than the effective depth $d$. The condition that $d_{\text {eff }}$ does not exceed $d$ can be written as:

$$
l_{1, \min }=\frac{u_{o} \times\left[a+0.5\left(r_{b}-r_{t}\right)\right]}{d-u_{o}}
$$

If the actual anchorage length is less than the minimum anchorage length defined by Eq.(20), the effective width of concrete strut must be calculated by substituting $u_{o}$ for $y$ in Eq.(18) and $d$ for $d_{e f f}$ in Eq.(19). In this case, the effective width of concrete strut is equal to the one given by both the CEB-FIP Model code and the CSA Concrete code [see Fig.5(b)].

Checking of the concrete strut pressure $\sigma_{c l}$ with respect to $f_{c e 2}$ is normally sufficient for the $C C T$. node. However, if the tension tie is anchored by an anchor plate or is arranged in several layers with transverse ties, the pressure $\sigma_{c l}$, can be checked with respect to $f_{c e l}$.

\section{b) Hydrostatic nodal model}

For the hydrostatic node, the stress states inside the nodal areas are homogeneous, i.e. the stresses along the sides of node are equal to $\sigma_{c l}$. The fanshaped transition stress fields with the slope of $45^{\circ}$ are used to enlarge the stress fields above the supporting blocks, because the strengths of the $C C T$-nodes $f_{c e 2}$ were considerably lower than the actual bearing stresses for most of the deep beams with $a / d \leqq 1.0$, which failed in shear or web crushing mode, not in bearing mode.

For a given $\theta$, the effective width of concrete strut $w_{\text {eff }}^{b}$ can be determined by :

$$
\begin{aligned}
w_{\text {eff }}^{b} & =\frac{r_{b}+2\left(u_{o}-y\right)}{\sin \theta} & & \text { for } y \leq u_{o} \\
& =\frac{2 u_{o}}{\cos \theta} & & \text { for } y>u_{o}
\end{aligned}
$$

where $y=\frac{T}{2 b f_{c e 2}}$

As can be seen from Eq.(21) and Eq.(22), the effective width of concrete strut for hydrostatic node model is closely related to the force $T$. 
(3) The required force of the tension tie

Since the force of the strut $D_{b}$ contacted with the $C C T$-node is determined by the value of $w^{b}{ }_{e f f}$, the force $T$ at this location is also limited by the detailing of the nodes, because the horizontal component of $D_{b}$ must be equal to $T$ [see Eq.(15)].

In order to determine the effective compressive strength of the strut $f_{c e \text { e? }}$ at the $C C T$-node, the required force in tension tie $T_{a}$ should be determined firstly by using $f_{c e 2}^{i}$ as defined in Eq.(7).

Substituting Eq.(17) into Eq.(15) for $D_{b}$ gives:

$$
T=b f_{c e 2} w_{e f f}^{b} \cos \theta
$$

or

$$
T_{a}=b f^{i}{ }_{c e 2} w_{e f f}^{b} \cos \theta
$$

and replacing $w^{b}{ }_{\text {eff }}$ in Eq.(23) by Eq.(18) and Eq.(21) the following relationships can be obtained.

For non-hydrostatic nodal model, the required tension force $T_{a}$ is

$$
T_{a}=b f_{c e 2}^{i}\left(r_{b} \sin \theta+2 y \cos \theta\right) \cos \theta
$$

and for $l_{l} \leqq l_{l, m i n}$, putting $y=u_{o}$ in Eq.(24), then $T_{a}$ is given by:

$$
T_{a}=b f_{c e 2}^{i}\left(r_{b} \sin \theta+2 u_{o} \cos \theta\right) \cos \theta
$$

If a special anchorage device is provided for tension ties, $T$ is equal to $T_{a}$ and can be calculated directly by using $f_{\text {cel }}$.

$$
T=b f_{c e l}\left(r_{b} \sin \theta+2 u_{o} \cos \theta\right) \cos \theta
$$

For hydrostatic nodal model, the required tension force $T_{a}$ is calculated by:

$$
T_{a}=\frac{b f_{c e 2}^{i}\left(r_{b}+2 u_{o}\right)}{1+\tan \theta} \leq 2 b u_{a} f_{c e 2}^{i}
$$

By substituting $T_{a}$ into Eq.(8), the effective compressive strength $f_{c e 2}$ will be determined. Hence, the tension force $T$, which gives the maximum compressive force for the concrete strut is calculated as follows:

$$
T=\beta T_{a} \leq T_{\max }
$$

where $\beta$ is the effective compressive strength ratio, and should be greater than or equal to one.

$$
\beta=\frac{f_{c e 2}}{f_{c e 2}^{i}} \geq 1.0
$$

\section{MODELLING AND ANALYSIS PROCEDURE}

There are no unique or absolute solutions in the application of strut-and-tie models. To obtain a satisfactory solution, the strut and tie members of

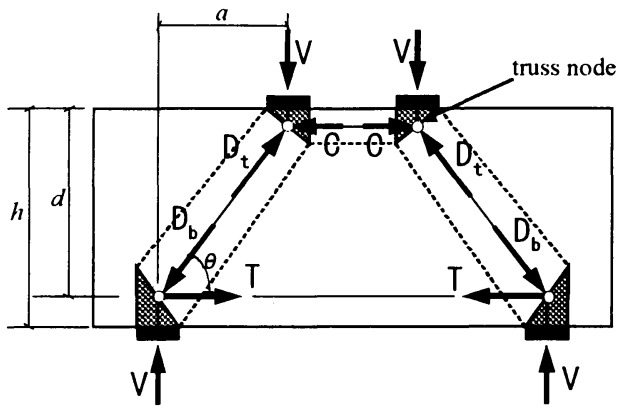

Fig.7 Truss models for the beams without stirrups

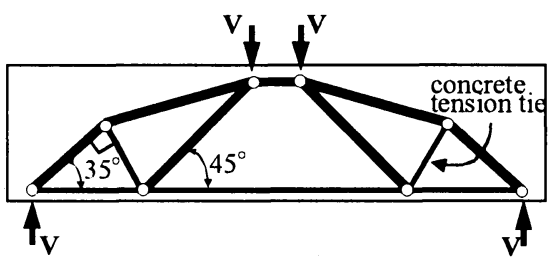

Fig.8 Truss model with concrete tension members for the beams with shear span-to-depth ratio $\leqq 2.0^{17}$ )

the developed models must follow the force flow that takes the shortest path between two loading points or node points.

\section{(1) Beams without shear reinforcement}

For deep beams without shear reinforcement, the flow of forces at their ultimate limit state can be modeled with a statically determinate truss system as shown in Fig.7. This model is made up of only concrete compression struts and steel tension ties, and takes the shortest load path between loading point and support point. A sophisticated model using concrete tension ties was proposed by Khaled et al. ${ }^{17)}$ as shown in Fig.8. In their study, the predicted failure loads by using the simple truss model shown in Fig.7 were found to be much higher than the actual failure loads for the beams without shear reinforcement which were tested by them. However, the reason for these discrepancies may result from the effective compressive strength of the struts and the $C C T$-nodes. In fact, $0.6 f_{c k}$ was used as the effective compressive strength for the struts and the $C C T$-nodes in their study, and no parameters which have a strongly effect on the effective strength of concrete were considered.

If struts and ties have reached to their capacity simultaneously, the beam will fail by the crushing of strut after yielding of tension tie. But in fact the possibility to occur this type of failure is very low. The type of failure most relevant to deep beams is shear or shear-compression failure in web. In this case, ultimate strength of the beam will be 
controlled by the capacity of the strut. Flexural failure will also occur if the amount of main reinforcement is very small, and then the capacity of strut is greater than that of tie. The tension forces in reinforcing bars are permitted to $T_{\max }\left(=A_{s} f_{y}\right)$ in proposed strut-and-tie models, where $A_{s}$ is total area of the longitudinal reinforcing bars and $f_{y}$ is its yield stress. The effect of strain hardening for steels after yielding was not considered in this study.

There are two unknowns, $T$ and $V$, in the model shown in Fig.7. To obtain the ultimate capacity of the beam, the tension force $T$ should be determined firstly, which vary with $\theta$. And until to failure, the equilibrium conditions between struts and ties at the nodes must be kept. Therefore, the following trial and error technique should be used to solve the problem:

1) Calculate $f_{c e l}$ from Eq.(1) and $f_{c e 2}^{i}$ from Eq.(7).

2) Assume $d_{a}$ as follows:

$$
d_{a}=\left(d_{a}{ }^{\min }+d_{a}{ }^{\max }\right) / 2
$$

where the initial value of $d_{a}^{\text {min }}=0$ and $d_{a}^{\text {max }}=d$

3) Calculate $\theta$ from Eq.(12) for hydrostatic node and Eq.(19) for non-hydrostatic node.

4) Calculate $T_{a}$ from Eq.(24),(25),(26), and (27).

5) Calculate $f_{c e 2}$ from Eq.(8) and $\beta$ from Eq.(29).

6) Calculate $T$ from Eq.(28).

7) Calculate $D_{b}$ from Eq. (17) and $D_{t}$ from Eq. (14).

8) Check that $D_{b}=D_{t}$. If $D_{b} \neq D_{t}$, return to Step 2) with $d_{a}^{\text {min }}=d_{a}$ for $D_{b}>D_{t}$ or $d_{a}^{\text {max }}=d_{a}$ for $D_{b}<D_{t}$.

9) Calculate $\sigma_{b}$ and $\sigma_{c 2}$ as

$$
\begin{gathered}
\sigma_{b}=\frac{D_{t} \sin \theta}{b r_{t}} \\
\sigma_{c 2}=\frac{D_{t} \cos \theta}{b d_{a}}
\end{gathered}
$$

10) Calculate $f_{2 c k}$ from Eq.(9) and $\alpha$ from Eq.(10).

11) Check $\sigma_{c 2} \leqq f_{2 c k}$. If not, adjust $d_{a}$ as:

$$
d_{a}=\frac{D_{t} \cos \theta}{b f_{2 c k}}
$$

Return to Step 3) and omit Step 8) from the routine above.

12) Calculate the ultimate capacity of the beam.

$$
V=D_{t} \sin \theta
$$

For non-hydrostatic nodal model with $l_{l} \geqq l_{l, m i n}$, it is necessary to repeat above calculations for a range of $l_{l}$ values starting from $l_{l, \text { min }}$ and increasing $l_{l}$ until the ultimate capacity of the beam reached its maximum value. A computer program based on the
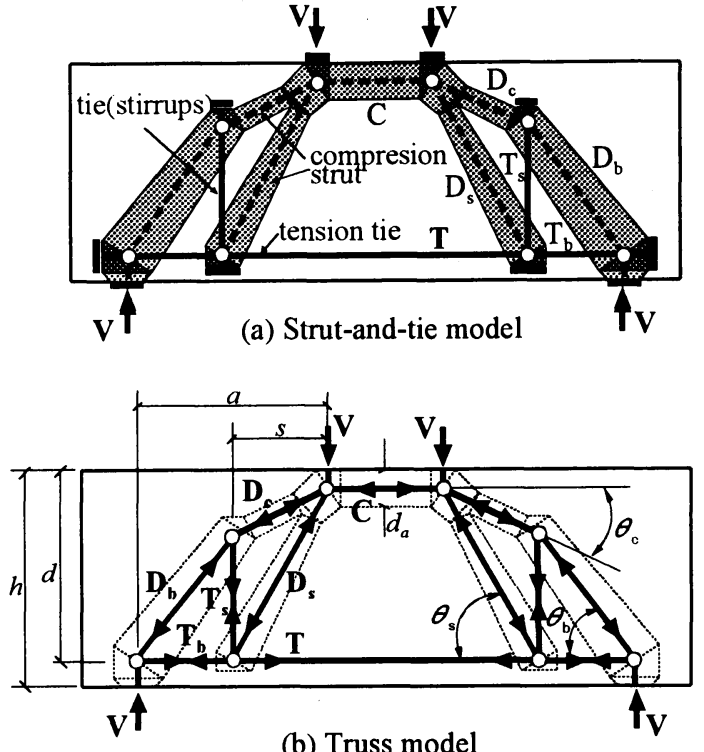

(b) Truss model

Fig.9 Proposed STM model for beams with stirrups

above calculation procedures was developed by the authors, and the flow chart for this program described in Appendix A.

\section{(2) Beams with vertical web reinforcement}

For beams without stirrups $(1.0<a / d<2.5)$, the diagonal crack forms independently and not as a development of a flexural crack. The beam usually remains stable after such cracking. The penetration of the diagonal crack deeply into the compressive zone reduces the effective cross-sectional area of the zone and thus leads to crushing failure of the concrete near the loading points.

Previous investigations ${ }^{18), 19), 20), 21)}$ have indicated that the addition of stirups will delay the formation and spreading of the diagonal cracks and also reduce the width of the cracks. Further, stirrups have the tendency to prevent the diagonal cracks from penetrating into the compressive zone. However, the effect of vertical stirrup decreases as $\mathrm{a} / \mathrm{d}$ decreases and is not proportional to the amounts of stirrups for deep beams with $a / d<2.5$ as its in slender beams. For short beams $(1.0<a / d<2.5)$ with stirrups, truss action is fairly obvious, as well as arching action. To obtain a satisfactory solution, thus, a rational model which can considers both arch and truss effects must be introduced.

A strut-and-tie model for deep beams with stirrups is presented in Fig.9. The applied load $V$ is transmitted to the support of the beam by the compressive struts, $D_{c}$ and $D_{s}$. The inclined angle of these struts should be limited in $25^{\circ} \leqq \theta_{s} \leqq 65^{\circ}$ for 
$D_{s}$ and $\theta_{c} \geqq 0^{\circ}$ for $D_{c}$. From equilibrium condition at the intersection of $D_{s}$ and $T$, the horizontal component of the force $D_{s}$ must be equal to the difference between the forces $T$ and $T_{b}$ in the tension ties formed by the longitudinal reinforcement on the either side of the node. The vertical component of the force $D_{s}$ must also be equal to the forces $T_{s}$ in the stirrups. Furthermore, the maximum force $T_{s}^{\text {max }}$ which can be carried by the tie $T_{s}$ depends on both the total area of stirrups in pure shear span $A_{s v}$ and its yield stress $f_{v y}$. If the required force in the stirnup which satisfies both the equilibrium and geometric conditions is greater than $T_{s}^{\max }, T_{s}$ equals to $T_{s}^{\text {max }}$ and then, the angle of the strut $D_{b}$ and the force of the strut $D_{s}$ should be limited to the maximum force of the tie $T_{s}$. In this case, the stirrups corresponding to the tie $T_{s}$ will yield at failure. If $T_{s}$ is less than $T_{s}$, ${ }^{\max }$ the force of the tie $T_{s}$ should be limited to the geometric conditions of the beam; in other words. the angle of the strut $D_{c}$ must be greater than zero. thus the stirrups will not yield at failure. The force of the tie $T_{s}$, therefore, should be determined by both considerations of the geometric condition of the beam and the material properties of stirrups.

As can be seen from Fig.9, vertical stirrups play the role of reducing the tension force of reinforcing bars and increasing the angle between the tie and the strut at the $C C T$-nodal zone. Thus, the effective compressive strength in the $C C T$-node will be increased as compared to that of beams without stirrups. As the result, required tension force of reinforcing bars at the $C C T$-node is increased, with a consequent increase in the tension force of tie at mid-span.

There are three unknowns, $T, T_{s}$ and $V$ in the model shown in Fig. 9. Then, to obtain the ultimate capacity of the beam, we should firstly determine both forces of $T$ and $T_{s}$, which vary with the values of $\theta_{b}$. From geometrical considerations for the truss model shown in Fig.9(b), the following relationship can be established:

$$
(a-s) \tan \theta_{b}+s \tan \theta_{c}=d-0.5 d_{a}
$$

From Eq.(34)

$$
\theta_{c}=\tan ^{-1}\left[\frac{\left(d-0.5 d_{a}\right)+(s-a) \tan \theta_{b}}{s}\right]
$$

where $s$ is the distance from the loading point to the center of stirrups provided in pure shear span.

From the equilibrium conditions, the following equations also can be established

$$
\begin{gathered}
D_{b} \sin \theta_{b}-D_{c} \sin \theta_{c}=T_{s} \\
D_{c}=D_{b} \cos \theta_{b} / \cos \theta_{c}
\end{gathered}
$$

$$
\begin{gathered}
D_{b}=T_{b} / \cos \theta_{b} \\
D_{c}=\left(T-D_{s} \cos \theta_{s}\right) / \cos \theta_{c}
\end{gathered}
$$

Substituting Eq.(36) for $D_{b}$ into Eq.(37) gives

$$
D_{c}=T_{s} /\left(\cos \theta_{c} \tan \theta_{b}-\sin \theta_{c}\right)
$$

Equating Eq.(39) and Eq.(40) leads to

$$
\theta_{c}=\tan ^{-1}\left(\tan \theta_{b}-T_{s} / T_{b}\right)
$$

Then, equating Eq.(35) and Eq.(41) leads to

$$
\theta_{b}=\tan ^{-1}\left[\frac{s}{a}\left(\frac{d-0.5 d_{a}}{s}+\frac{T_{s}}{T_{b}}\right)\right]
$$

For the strut-and-tie model shown in Fig.9 to be valid, the angle $\theta_{c}$ must be greater than or equal to zero. Thus, one of the upper limits for $\theta_{b}$ can be established by:

$$
\theta_{b}{ }^{g 1}=\tan ^{-1}\left(\frac{d-0.5 d_{a}}{a-s}\right)
$$

When non-hydrostatic nodal model is applied to this model, furthermore, one more upper limit for $\theta_{b}$ should be considered. The relationship between $V$ and $\theta_{b}$ can be obtained from Eq.(16), (17), and (18) with $\theta=\theta_{b}$

$$
V=b f_{c e 2}\left(r_{b} \sin \theta_{b}+2 u_{o} \cos \theta_{b}\right) \sin \theta_{b}
$$

It can be seen that $V$ vary with $\theta_{b}$. Then, the angle $\theta_{b}$ which gives the maximum value for $V$ can be obtained by the conditions $\partial V / \partial \theta_{b}=0$, which is

$$
\theta_{b}{ }^{g 2}=\frac{\pi}{2}-\frac{1}{2} \tan ^{-1}\left(\frac{2 u_{o}}{r_{b}}\right)
$$

Other equations required for calculating $V$ can be established directly from equilibrium conditions and geometrical considerations:

$$
\begin{gathered}
\theta_{s}=\tan ^{-1}\left[\left(d-0.5 d_{a}\right) / s\right] \\
T=T_{b}+T_{s} / \tan \theta_{s} \\
T_{s}=\left(T-T_{b}\right) \tan \theta_{s} \\
D_{t}=\left(D_{c} \sin \theta_{c}+D_{s} \cos \theta_{s}\right) / \cos \theta
\end{gathered}
$$

where $D_{t}$ is the resultant compressive force of $D_{\mathrm{c}}$ and $D_{s}$ at the $C C C$-node.

To calculate the ultimate capacity of the beam with stirrups, which has been discussed above, a trial and error technique is applied as follows:

1) Calculate $f_{c e l}$ from Eq.(1) and $f_{c 22}^{i}$ from Eq.(7).

2) Assume $d_{a}$ as follows:

$$
d_{a}=\left(d_{a}{ }^{\min }+d_{a}{ }^{\max }\right) / 2
$$

where the initial value of $d_{a}^{\min }=0$ and $d_{a}^{\max }=d$. 
Table 1 Parameters of test beams and the ratio of shear strength predictions to test results for beams without stirrups

\begin{tabular}{|c|c|c|c|c|c|c|c|c|c|c|c|}
\hline \multirow[b]{2}{*}{ Authors } & \multirow[b]{2}{*}{ Num } & \multicolumn{6}{|c|}{ Parameters of the specimens } & \multicolumn{4}{|c|}{ Average(c.v.,\%) } \\
\hline & & $f_{c k}(\mathrm{MPa})$ & $a / d$ & $r / d$ & $u_{0} / d$ & $\rho_{w}(\%)$ & $\boldsymbol{k}_{r}$ & STM & Niwa & CEB & CSA \\
\hline Mathey ${ }^{23)}$ & 16 & $21.8 \sim 27.0$ & 1.51 & 0.22 & 0.13 & $0.75 \sim 3.05$ & $0.39 \sim 0.75$ & $1.02(14.1)$ & $1.31(8.0)$ & $1.36(172)$ & $1.53(11.9)$ \\
\hline Morrow ${ }^{24)}$ & 17 & $13.7 \sim 47.2$ & $1.21 \sim 2.27$ & $0.27 \sim 0.29$ & 0.10 & $1.17 \sim 3.83$ & $0.23 \sim 0.81$ & $1.0 \times(122)$ & $1.28(12.1)$ & $1.50(222)$ & $1.86(22.3)$ \\
\hline Moody ${ }^{25)}$ & 12 & $17.2 \sim 25.0$ & 1.53 & 0.38 & 0.14 & $2.72 \sim 4.25$ & $0.30 \sim 0.54$ & $1.06(14.9)$ & $0.99(12.3)$ & $1.22(21.9)$ & $1.53(14.4)$ \\
\hline Ramakrishnan ${ }^{26)}$ & 8 & $16.4 \sim 28.4$ & $0.30 \sim 0.62$ & $0.10 \sim 0.22$ & $0.04 \sim 0.09$ & $0.34 \sim 0.75$ & $0.57 \sim 1.38$ & $0.97(17.4)$ & 0.71(11.6) & $1.05(242)$ & $1.09(26.6)$ \\
\hline Paiva ${ }^{27)}$ & 2 & $19.9 \sim 23.3$ & 1.00 & 0.50 & 0.13 & $1.67 \sim 2.59$ & $0.47 \sim 0.69$ & 1) & 1.8) & 1.2 & $1.36(19.8)$ \\
\hline Manuel ${ }^{28)}$ & 4 & $30.1 \sim 35.2$ & 0.30 & 0.37 & 0.13 & 0.97 & $0.79 \sim 0.85$ & $1.00(4.26)$ & 4.9) & $1.00(4.3)$ & $0.96(3.5)$ \\
\hline Walraven ${ }^{19)}$ & 14 & $13.9 \sim 26.4$ & 0.9 .3 & 0.13 & $0.11 \sim 025$ & $1.13 \sim 1.52$ & $1.10 \sim 1.82$ & $1.00(12.7)$ & $1.24(13.7)$ & $1.33(11.4)$ & $1.65(13.1)$ \\
\hline Kani ${ }^{29)}$ & 5 & $24.8 \sim 30.3$ & $1.00 \sim 2.46$ & $0.14 \sim 0.42$ & $0.10 \sim 0.16$ & $2.56 \sim 2.81$ & $0.18 \sim 0.76$ & $1.06(11.4)$ & $1.04(11.8)$ & $1.30(19.7)$ & $1.47(16.7)$ \\
\hline Smith ${ }^{18)}$ & 18 & $16.1 \sim 21.7$ & $1.00 \sim 2.08$ & 0.33 & 0.17 & 1.93 & $0.36 \sim 0.86$ & $1.12(7.2)$ & 1.19 & $1.53(8.6)$ & $1.35(14.5)$ \\
\hline Clark ${ }^{30)}$ & 10 & $21.5 \sim 26.2$ & $1.18 \sim 2.30$ & $0.11 \sim 0.23$ & 0.18 & 0.98 & $0.28 \sim 0.56$ & $0.96(7.9)$ & $1.17(222)$ & $0.96(7.9)$ & $1.13(12.5)$ \\
\hline Subedi $^{4)}$ & 5 & $22.7 \sim 43.2$ & $0.42 \sim 0.46$ & $0.12 \sim 0.22$ & $0.06 \sim 0.11$ & $0.89 \sim 1.48$ & $1.27 \sim 1.85$ & $1.32(14.9)$ & $1.16(7.5)$ & $1.35(16.3)$ & $1.82(15.5)$ \\
\hline Niwa ${ }^{10)}$ & 16 & $25.4 \sim 54.4$ & $0.50 \sim 2.00$ & $0.07 \sim 0.50$ & $0.06 \sim 0.25$ & $1.76 \sim 3.72$ & $0.21 \sim 1.63$ & $0.96(11.5)$ & $1.00(12.9)$ & $1.39(33.8)$ & $1.36(232)$ \\
\hline Furuuchi ${ }^{20)}$ & 9 & $14.9 \sim 31.9$ & $0.68 \sim 1.43$ & 0.19 & 0.13 & 2.55 & $0.70 \sim 1.80$ & $1.09(10.6)$ & $1.30(11.9)$ & $1.81(16.6)$ & $1.7(17.1)$ \\
\hline Hayashigawa $^{21)}$ & 11 & $17.0 \sim 24.8$ & $0.50 \sim 1.00$ & 0.19 & 0.13 & 2.46 & $0.80 \sim 2.19$ & $1.17(7.7)$ & $1.32(8.3)$ & $2.18(16.9)$ & $1.83(19.6)$ \\
\hline Ishibashi ${ }^{22)}$ & 15 & $25.7 \sim 40.6$ & $0.50 \sim 2.50$ & $0.25 \sim 0.50$ & $0.08 \sim 0.15$ & $2.09 \sim 2.87$ & $0.14 \sim 1.27$ & $1.08(15.3)$ & $1.04(15.9)$ & $1.45(32.9)$ & $1.63(23.7)$ \\
\hline
\end{tabular}

$\rho_{w}$ is the longitudinal tension reinforcement ratio $\left(=100^{*} A / b d\right)$

$k_{r}$ is the bearing stress ratio $\left(=\sigma_{b} / f_{c k}\right), \quad \sigma_{b}=V_{\text {exp }} b r, r$ is the smaller of $r_{b}$ and $r_{t}$

3) Calculate $\theta$ from Eq.(12) and $\theta_{s}$ from Eq.(46).

4) Calculate $\theta_{b}{ }^{g l}$ from Eqs.(43) and $\theta_{b}{ }^{g 2}$ from Eq. (45), and take the smaller values.

5) Calculate $T_{a}$ from Eqs.(25),(26), and (27) for $\theta=\theta_{b}{ }^{g}$.

6) Calculate $f_{c e 2}$ from Eq. (8) and $\beta$ from Eq.(29).

7) Calculate $T_{b}$ from Eq.(28) and $D_{b}$ from Eq.(17) for $\theta=\theta_{b}{ }^{g}$.

8) Calculate $\theta_{c}$ from Eq.(35).

9) Calculate $D_{c}$ from Eq.(37) and $T_{s}$ from Eq.(36).

10) Calculate a trial value of $\theta_{b 2}$ from Eq.(42).

11) Check that $\theta_{b}^{g}=\theta_{b 2}$. If $\theta_{b}^{g} \neq \theta_{b 2}$, return to Step 5) with $\theta_{b}{ }^{g}=\theta_{b 2}$.

12) Calculate $T$ from Eq.(47) and $T_{s}^{c}$ from Eq.(48), where $T_{s}^{c}$ is the required force which satisfies the equilibrium condition with main tension tie.

13) Calculate $\theta_{b 3}$ from Eq.(42) for $T_{s}=T_{s,}^{c}$ where $\theta_{k 3}$ is the angle of $D_{b}$ strut which satisfies the equilibrium condition with $T_{s}$ tie.

14) Check that $T_{s}=T_{s}^{c}$

If $T_{s}^{c}<0$, analysis using simple models.

If $T_{s}^{c}>0$, return to Step 5) with $\theta_{b}{ }^{g}=\theta_{b 3}$.

15) Calculate $D_{t}$ from Eq.(49) and $D_{t}^{m c x}$ from Eq.(14).

16) Check that $D_{t}=D_{t}{ }^{\max }$, If $D_{t} \neq D_{t}^{\max }$, then return to Step 4) with $d_{a}^{\text {min }}=d_{a}$ for $D_{t}>D_{t}^{\max }$ or $d_{a}^{\text {max }}=$ $d_{a}$ for $D_{t}<D_{t}^{\max }$.

17) Calculate $\sigma_{b}$ and $\sigma_{c 2}$ from Eq.(31)

18) Calculate $f_{2 c k}$ from Eq.(9) and $\alpha$ from Eq.(10)

19) Check $\sigma_{c 2} \leqq f_{2 c k}$. If not, adjust $d_{a}$ as using Eq.(32). Return to Step 3) and omit Step 16) from the routines above.
20) Calculate the ultimate capacity of the beam.

$$
V=D_{t} \sin \theta
$$

To calculate the ultimate capacity of the beam, both typical non-hydrostatic nodal model $\left(l_{l}=l_{l, \min }\right)$ and hydrostatic nodal model are used. A computer program based on the calculation procedure above was developed and the flow diagram for the program is described in Appendix B.

\section{VERIFICATION AND DISCUSSION}

The validity of the proposed models was examined by comparisons with experimental data in many other works published to date. The test data were selected on the bases of the following:

(a) The beams must fail in web shear mode or in shear-compression mode before or after yielding of the main reinforcements, not in bearing or flexural mode.

(b) The value of $a / d$ must be less than or equal to 2.5 .

(c) The beams failed by shear in the web before or after yielding of the vertical stirrups.

(d) The beams must be simply supported with one or two concentrated loading.

Details of the test data are listed in Table 1 and Table 2, where STM means the proposed method. The selected experimental data have an extensive range of parameters that give most information about the ultimate behavior of simply supported deep beams. 


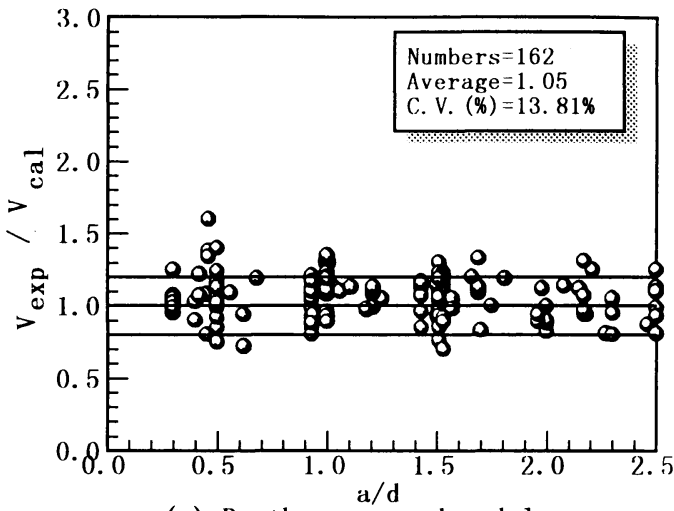

(a) By the proposed models

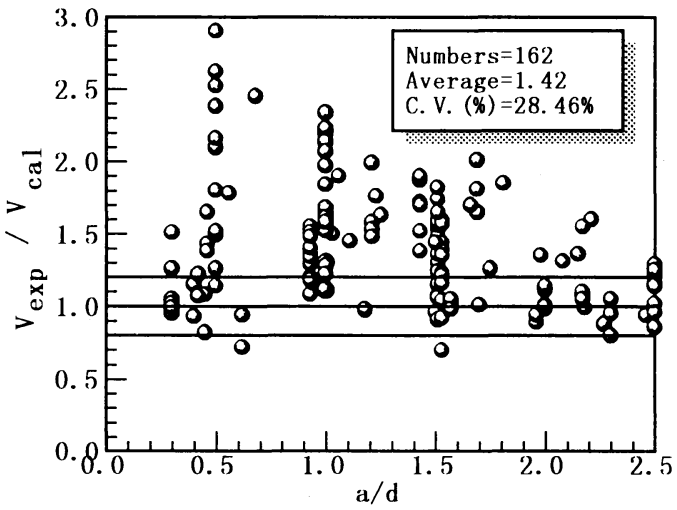

(c) By the CEB-FIP Model Code

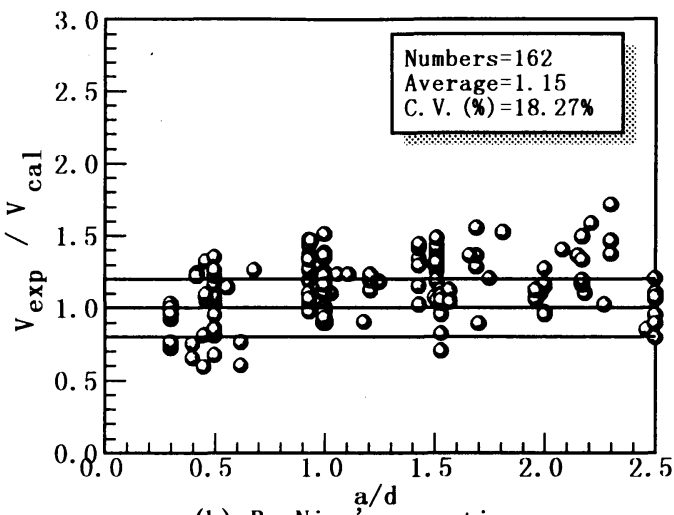

(b) By Niwa's equation

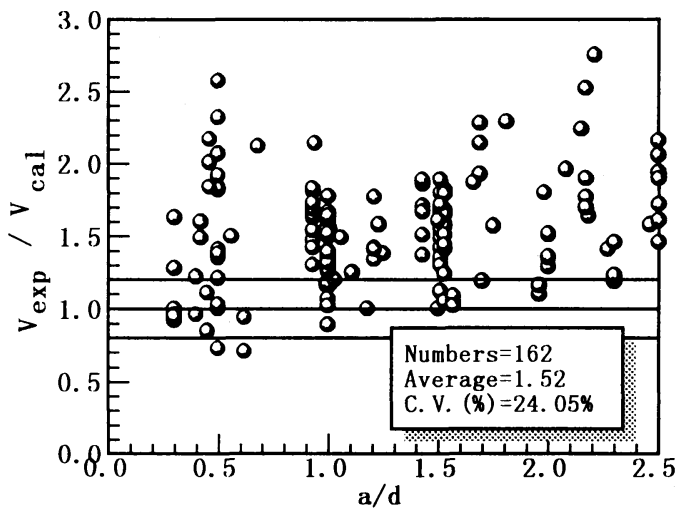

(d) By the CSA Concrete Code

Fig. 10 Comparison of measured and calculated failure loads for beams without stirrups

\section{(1) Beams without stirrups}

Experimental results of the tested beams listed in Table 1 are compared to predicted failure loads using the proposed method in this study, Niwa's equation, the CEB-FIP Model code, and the CSA Concrete code. The beams with stirrups are also included in Table 1, when ald is less than or equal to one.

Niwa ${ }^{10)}$ proposed a detailed design equation based on both non-linear finite element analysis and experimental results for simply supported deep beams without stirrups. This equation usually gives a good prediction of shear strength for deep beams within a wide range of parameters and it is the basis of the formulas in the JSCE Concrete code:

$$
V=\frac{0.2444 f_{c k}^{2 / 3}\left(1+\sqrt{\rho_{w}}\right)(1+3.33 r / d) \cdot b d}{1+(a / d)^{2}}
$$

where $f_{c k}$ is compressive strength(MPa) and $r$ is the width of bearing plate.

Fig.10 shows the comparison between measured and predicted values using four methods above for a total of 162 test beams. The ratio $V_{e x p} / V_{c a l}$, where
$V_{\text {exp }}$ is the measured strength and $V_{c a l}$ is the calculated strength, is an indication of the correlation between them. As can be seen from Fig.10a, the proposed model gives the lowest coefficient of variation of $13.81 \%$ among the four methods, and a mean of 1.05 . For beams tested by Paiva et al. ${ }^{27)}$ and Subedi ${ }^{4)}$, however, the proposed models gives conservative results as shown in Table 1: a mean value of 1.21 and 1.32 , respectively. These results may be caused by the failure modes of beams and by the local confining reinforcements under the loading areas and above the supports. Paiva's beams failed in flexure-shear mode or in shear after yield of tension reinforcement and Subedi's beams failed in diagonal splitting of webs accompanied by local crushing and spalling of concrete at loading or support regions. These beams, also, have a very high level of bearing stress within a range from $1.27 f_{c k}$ to $1.85 f_{c k}$ under loading blocks at failure (see Table 1).

One of the decisive factors affecting the widths of concrete struts in strut-and-tie models is the length of bearing plates, as can be seen from Eq.(11) and (18). Furthermore, the effective compressive 
Table 2 Parameters of test beams and the ratio of shear strength predictions to test results for beams with stirrups

\begin{tabular}{|c|c|c|c|c|c|c|c|c|c|c|c|}
\hline \multirow[b]{2}{*}{ Authors } & \multirow[b]{2}{*}{ Num } & \multicolumn{6}{|c|}{ Parameters of the specimens } & \multicolumn{4}{|c|}{ Average(c.v., \%) } \\
\hline & & $f_{c k}(\mathrm{MPa})$ & $a / d$ & $\bar{r} / d$ & $\rho_{w}(\%)$ & $\rho_{s}(\%)$ & $\boldsymbol{k}_{r}$ & STM & Niwa & CEB & CSA \\
\hline Smith ${ }^{18)}$ & 47 & $16.1 \sim 22.7$ & $1.00 \sim 2.08$ & 0.33 & 1.93 & $0.18 \sim 1.25$ & $0.52 \sim 0.86$ & $1.09(5.4)$ & $1.36(14.8)$ & $1.30(72)$ & $1.14(8.5)$ \\
\hline Clark ${ }^{30)}$ & 50 & $13.8 \sim 47.6$ & $1.16 \sim 2.43$ & $0.11 \sim 028$ & $1.63 \sim 3.43$ & $0.34 \sim 1.22$ & $0.39 \sim 1.10$ & $0.99(8.5)$ & $1.57(23.7)$ & $1.08(9.5)$ & $1.07(10.8)$ \\
\hline Rogowsky $^{31)}$ & 6 & $26.1 \sim 4.3 .2$ & $0.97 \sim 2.09$ & $0.16 \sim 0.28$ & $0.88 \sim 1.12$ & $0.19 \sim 0.23$ & $0.23 \sim 0.93$ & $1.16(6.8)$ & $1.12(7.8)$ & $1.23(10.8)$ & $1.15(9.7)$ \\
\hline $\operatorname{Tan}^{32)}$ & 8 & $41.1 \sim 50.6$ & $1.08 \sim 2.16$ & 0.14 & 1.23 & 0.48 & $0.50 \sim 0.86$ & $1.11(6.8)$ & $1.36(16.5)$ & $1.11(6.6)$ & $1.09(6.7)$ \\
\hline Moody ${ }^{25)}$ & 2 & $22.4 \sim 25.4$ & 1.53 & 0.38 & 4.25 & $0.52 \sim 0.95$ & $0.52 \sim 0.63$ & $1.08(4.6)$ & $1.23(10.3)$ & $1.07(4.3)$ & $1.20(2.0)$ \\
\hline Subedi ${ }^{4)}$ & 5 & $29.6 \sim 43.2$ & $0.99 \sim 1.53$ & $0.13 \sim 0.22$ & $0.89 \sim 1.48$ & $0.20 \sim 0.63$ & $0.51 \sim 1.30$ & $1.20(10.1)$ & $1.25(15.5)$ & $1.23(8.2)$ & $1.25(152)$ \\
\hline Walraven ${ }^{19)}$ & 8 & $17.0 \sim 21.3$ & 0.94 & 0.13 & $1.10 \sim 1.50$ & $0.22 \sim 0.65$ & $1.19 \sim 2.26$ & $1.11(8.2)$ & $1.42(18.7)$ & $1.40(8.0)$ & $1.95(21.9)$ \\
\hline Niwa ${ }^{33)}$ & 8 & $34.3 \sim 53.7$ & $1.00 \sim 2.07$ & $0.06 \sim 0.31$ & $3.72 \sim 5.37$ & $0.45 \sim 2.31$ & $0.47 \sim 2.91$ & $1.00(7.2)$ & $1.31(19.7)$ & $1.13(10.9)$ & $1.02(5.5)$ \\
\hline Nishigawa $^{34)}$ & 7 & $20.4 \sim 23.3$ & $1.00 \sim 1.25$ & 0.50 & 1.91 & $0.17 \sim 0.84$ & $0.45 \sim 0.63$ & $1.11(8.9)$ & $1.06(8.0)$ & $1.27(9.9)$ & $1.21(11.0)$ \\
\hline Furuuchi ${ }^{20)}$ & 10 & $14.8 \sim 37.0$ & $1.43 \sim 1.81$ & 0.19 & 2.55 & $0.14 \sim 1.00$ & $0.66 \sim 1.27$ & $1.19(14.4)$ & $1.60(21.1)$ & $1.51(15.9)$ & $1.26(17.3)$ \\
\hline Hayashigawa $^{21)}$ & 8 & $17.0 \sim 25.1$ & $1.00 \sim 2.00$ & 0.19 & 2.46 & $0.43 \sim 1.20$ & $0.78 \sim 1.48$ & $1.26(6.1)$ & $1.36(14.8)$ & $1.69(14.9)$ & $1.41(14.6)$ \\
\hline
\end{tabular}

strengths of the struts are limited to less than $0.85 f_{c k}$ in this study. But, for the beams $(a / d \leqq 1.0)$ with a heavy local confining reinforcement, such as Subedi's beams, the effective compressive strength of concrete struts near nodal zones will be greater than $0.85 f_{c k}$, due to lateral confinement by these reinforcements. As a result, the allowable force in the tie is increased in comparison with the beam without confinement reinforcement. In these cases, the beams failed by crushing of concrete under loading blocks or by spalling and crushing above the supports. The proposed model does not consider these failure modes, and it is only applicable to the beam which fails by the spreading of the diagonal crack from the load position to the support or by the crushing of the concrete struts between two diagonal cracks.

Niwa's equation give relatively good agreement between measured and predicted values; a coefficient of variation is $18.27 \%$ and a mean of 1.15. It is worth noting that, for tested beams by Paiva et al. and Subedi, prediction using Niwa's equation is more accurate than the proposed methods. These results may arise from the following reasons. Because 1) Niwa's equation is expressed in main reinforcement ratio, then the shear strength of the beam will be determined by the amount of tension reinforcement, not by the force in tension tie. And 2) there are no limits to stresses for the regions under loading points or the over supporting points, where highly compressive stresses occur locally. Therefore, for the beams which failed by shear after yielding of main reinforcements as in Paiva's beams and have local confining reinforcements at loading or support regions as in Subedi's beams, Niwa's equation usually will give a better result compared to the approach of strut-and-tie model.
Both the CEB-FIP Model code and the CSA Concrete code give very conservative predictions for most of the tested beams; a mean of 1.42 and a coefficient of variation of $28.46 \%$ by the CEB-FIP, 1.52 and $24.05 \%$ by the CSA. These results may be caused by the methods of treating the nodes and the effective concrete strength. For detailing of the nodes, both codes restricted the nodal areas within $r$ $\left(r_{b}\right.$ or $\left.r_{t}\right)$ and $2 u_{o}$ (see Fig.5b), thus the calculated tension force in the tie is also limited by these geometrical parameters. If the dimensions of $r$ and $u_{o}$ are big enough to develop the full capacity of tension tie, the nodes can be modeled using both codes. But, in fact, most of the tested beams had relatively small values of $r$, and the main reinforcing bars were anchored by bonding with transverse reinforcement, with the result that small values of $u_{o}$ were used, too. For these beams, the results obtained from both codes were generally and significantly below the measured failure loads.

\section{(2) Beams with stirrups}

The CSA Concrete code has no provisions for modeling of the deep beams with stirrups $(a / d<2.5)$. The CEB-FIP Model code has presented a truss model for deep beams to reflect the effect of stirrups. The code also have proposed a conservative approximate expression to determine the force in stirrup as a function of the ratio $a / z$ ( $z$ is the length of lever arm at the mid-section) and of the resultant axial and shear forces. But, the expression only can be applied when $V$ is known, thus this expression cannot be applied directly to calculate the ultimate capacity of the beam. Therefore, a truss model shown in Fig.9 is applied for modeling the beam with stirrups, while the procedures of detailing the nodes and determining the effective concrete strength are followed by the provisions described in 


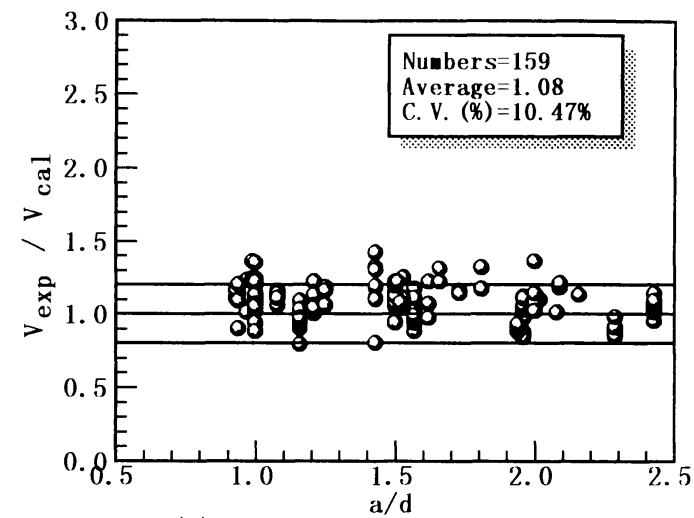

(a) By the proposed models

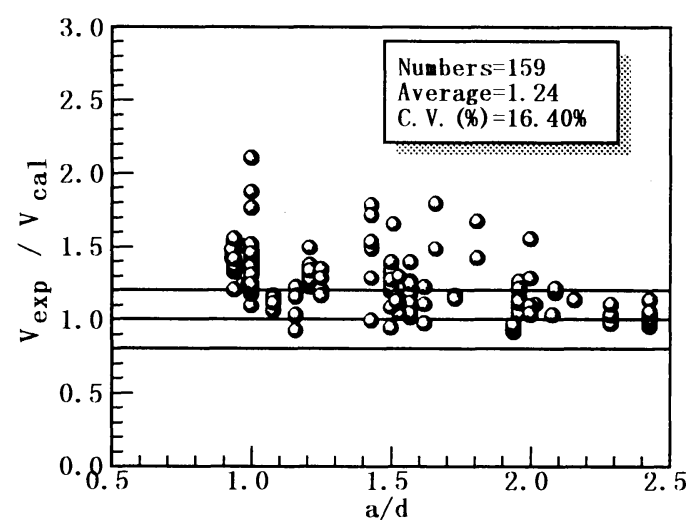

(C) By the CEB-FIP Mode1 Code

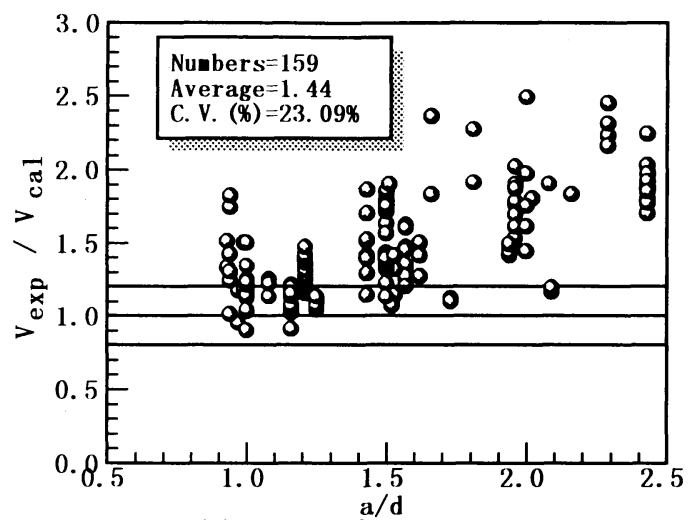

(b) By Niwa's equation

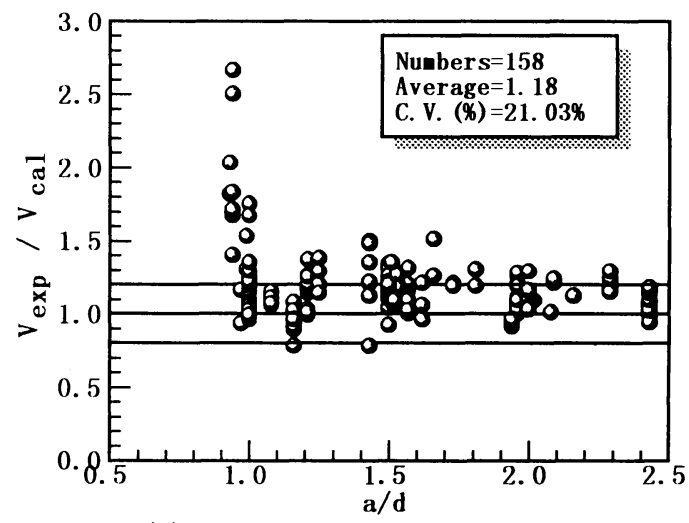

(d) By the CSA Concrete Code

Fig. 11 Comparison of measured and calculated failure loads for beams with stirrups

both codes. The relationships between the measured and the predicted failure loads were shown in Fig. 11. The proposed model gives very good results for all over total specimens, despite of a wide range of parameters; the mean and coefficient of variation of the ratio $V_{\text {exp }} / V_{\text {cal }}$ for 159 specimens are 1.08 and $10.47 \%$, respectively, as shown in Fig. 11(a).

By contrast the case for the beams without stirrups, Niwa's equation [see Eq.(50)] generally tends to underestimate the shear strength of deep beams with stirrups; a mean of 1.44 and a coefficient of variation of $23.09 \%$ for $V_{\text {exp }} / V_{\text {cal }}$. respectively. It can be also seen that the conservation increases with increasing $a / d$ from Fig. 11(b). From these results, it is clear that the presence of stirrups increases the ultimate shear strength of deep beams and thus Niwa's equation which does not consider the effectiveness of stirrups may not be suitable for beams with stirrups when a/d is greater than 1.0.

The CEB-FIP Model code gives a little conservative result with a mean of $V_{e x p} / V_{c a l}$ is 1.24 and a coefficient of variation of $16.40 \%$, respectively. It is worth noting that the conservation decreases with increasing a/d as shown in Fig. 11(c) Although the same truss model has been applied to both the CEB-FIP Model code and the proposed model, the result was different considerably from each other, especially in the beams when ald is less than 2.0. Both models have a difference on determining the effective compressive strength at the $C C T$-nodes, $f_{\text {ce2 }}$. In order to determine $f_{c e 2}$, the CEB-FIP Model code considers only the strength of concrete [see Eq.(2)], while the proposed model takes into account the parameters such as concrete strength, the disturbance from reinforcing bars, and $a / d$. Therefore, it can be concluded that the effective compressive strength for the $C C T$-nodes should be determined by taking into account the shear span/depth ratio and the disturbance from the reinforcing bars when ald is less than 2.0.

The CSA Concrete code gives relatively good agreement between measured and predicted values: a mean of 1.18 and a coefficient of variation of 21.03 for $V_{\text {exp }} / V_{c a l}$. But, for beams with ald less than or equal to one, the predictions are very conservative. The reason for this may result from limiting of bearing stress in the CSA Concrete code. 
In applying strut-and-tie models to disturbed regions, the CSA Concrete code limits the bearing stress under loading points to $0.85 f_{c k}$. However, for most of tested beam with $a / d \leqq 1.0$, the bearing stress of the beams which failed in shear or web crushing mode was much greater than $0.85 f_{c k}$ as listed in Table 2. For $a / d>1.0$, the predictions using the CSA Concrete code are fairly good compared to the CEB-FIP Model code. Unlike the CEB-FIP Model code, the CSA Concrete code takes into account the disturbances from reinforcing bars for determining the effective compressive strength of the $C C T$-nodes. As prescribed above, vertical stirrups play the role of reducing the tension force in reinforcing bars at the CCT-nodal zones, thus the disturbance from reinforcement will be reduced at this region. As the result, the effective compressive strength in the $C C T$-nodes is increased. Thus, it may be concluded that the effective compressive strength should be determined by taking into account the disturbance from reinforcing bars, as well as the ald ratio.

\section{CONCLUSIONS}

Based on the results of this study, the following conclusions can be made:

(1) The presented strut-and-tie models for simply supported deep beams are fairly adequate for predicting the ultimate capacity of the beam with and without stirrups when the beams failed in shear before yielding of main reinforcement. But, for the beams which failed by shear after yielding of the longitudinal reinforcements or which have local confining reinforcements at the loading and support regions, the presented methods gave a little conservative predictions.

(2) For beams without stirrups, Niwa's equation gave relatively good agreement between measured and predicted values. When the beams failed by shear after yielding of main reinforcement or the local confining reinforcements at the loading and support regions were provided, Niwa's equation gave the best results among the four methods.

(3) Both the CEB-FIP Model code and the CSA concrete code gave a very conservative prediction for most of the tested beams without stirrups. These discrepancies result from the method of treating the $C C T$-node and the effective compressive strength for concrete struts.

(4) For beams with stirrups, Niwa's equation, which does not consider the effectiveness of stirrups, gave the most conservative predictions among the four methods considered here. A further supplements are required to make this equation suitable for deep beams with stirrups when $a / d>1.0$

(5) The accuracy of strut-and-tie models is greatly dependent on detailing of the nodal zones and the effective compressive strength. When beams have a relatively small value of $r$ and $u_{o}$, the nodal models described in both the CEB-FIP Model code and the CSA Concrete code are not suitable. The proposed effective compressive strength for the $C C T$-node, which is a function of the strength of concrete, the shear-span ratio, and the disturbance from the reinforcing bars, was found useful to deep beams with $a / d<2.5$.

(6) The proposed methods for modeling the $C C T$ nodes were found useful to the beams having a relatively small value of $r$ and $u_{o}$, with transverse reinforcements within the anchorage regions over the supports.

\section{APPENDIX A}

Flow chart for the beams without web reinforcement

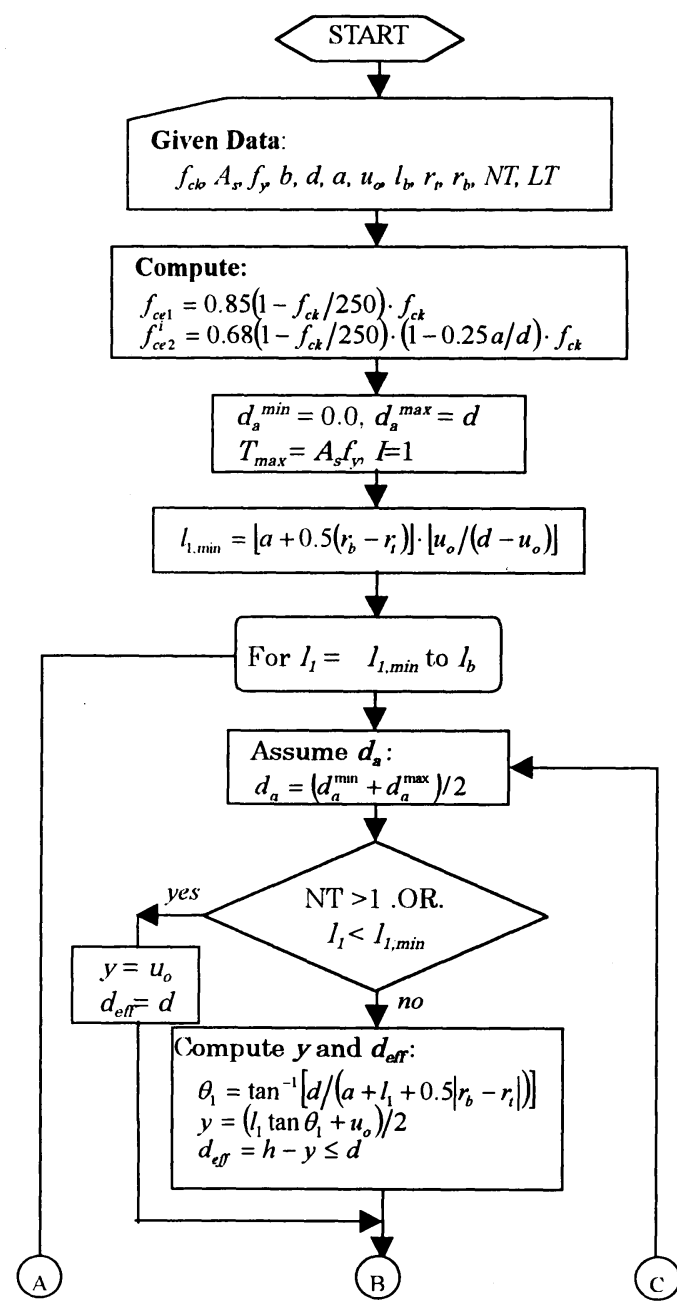




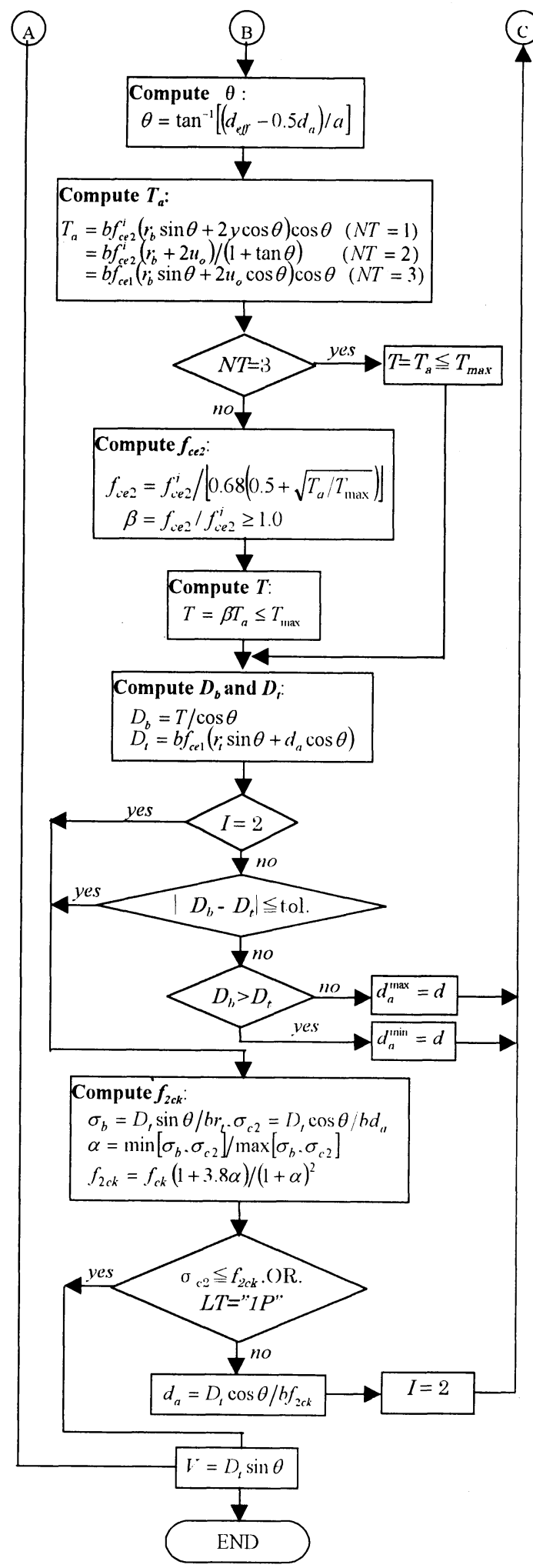

Fig. A Flow chart for program simple_STM
APPENDIX B

Flow chart for the beams with vertical web reinforcement

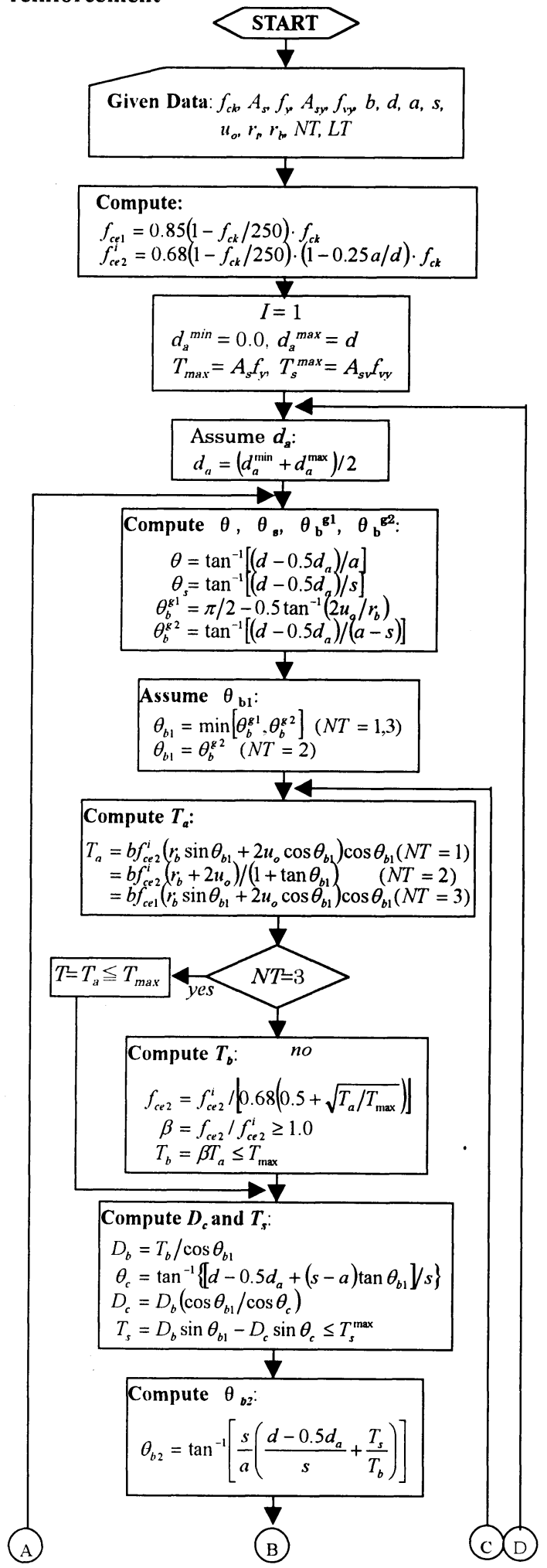




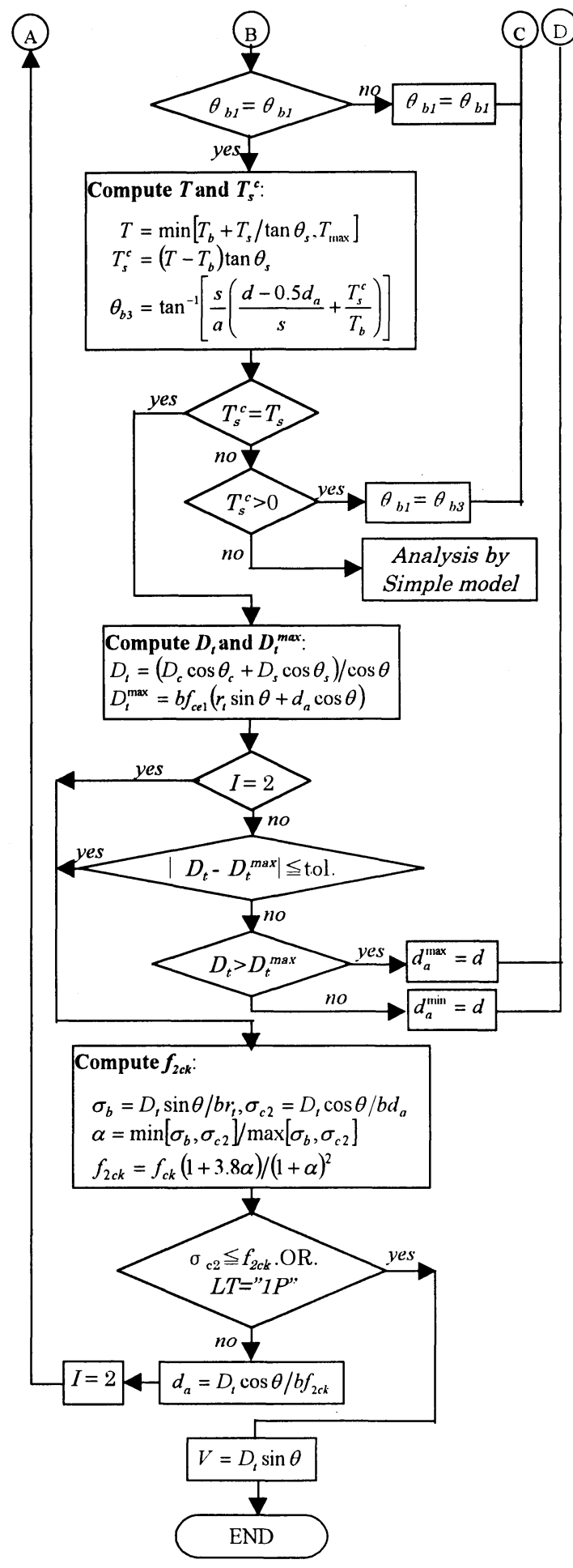

Fig. B Flow chart for program Vertical_STM

Note: $L T$ is loading type (1P or $2 \mathrm{P})$

$N T$ is node type (1=non-htdrostaic nodal model $2=$ hydrostaic nodal model. $3=$ active nodal model)

\section{REFERENCES}

1) Zsutty, T.C.: Shear strength prediction for separate categories of simple beam tests, ACI Journal, Proceedings V. 68, No. 2, pp. 138-143, Feb. 1971.

2) Kong, F. K., Robins, P.J., Singh, A., and Sharp G.R.: Shear analysis and design of reinforced concrete deep beams, The Structural Engineer(London), V. 50, No. 10, pp. 405-409, Oct. 1972

3) Kotsovos, M.D.: Design of reinforced concrete deep beams, The Structural Engineer (London), V. 66, No. 2, pp. 28-32, Jan. 1988.

4) Subedi, N.K.: Reinforced concrete deep beams - a method of analysis, Proceeding of ICE, Part 2, 85, pp. 1-30, March 1988.

5) JSCE: Standard specification and construction of concrete Structures - 1986 Part I (Design), JSCE 1986 (in Japanese).

6) Schlaich, J., Schafer, I., and Jennewein, M.: Towards a consistent design of structural concrete, PCI Journal, V. 32, No. 3, pp. 74-150, May-June 1987.

7) Collins, M.P., and Mitchell, D.: A rational approach to shear design - The 1984 Canadian Code Provisions, ACI Journal, Proceedings V. 83, No. 6, pp. 925-933, Nov.-Dec. 1986.

8) CSA Technical Committee: Design of Concrete Structures, CSA Standard A23.3-94, Rexdale, Ont., 1994.

9) CEB-FIP Model Code for concrete structures, MC 90, Lausanne, Comite Euro-International du Beton, 1993.

10)Niwa, J.: Equation for shear strength of reinforced concrete deep beams based on FEM analysis, Proceedings of JCI 2nd Colloquium on Shear Analysis of RC Structures, pp. 119126, Oct. 1983(in Japanese).

11)Won, D.Y., Hino, S., and Ohta, T.: A theoretical study on ultimate strength of simply-supported reinforced concrete deep beams, Journal of Structural Eng., JSCE, V. 42A, pp. 1105-1114, March 1996(in Japanese).

12)Vecchio, F.J., and Collins, M.P.: Modified compression field theory for reinforced concrete elements subjected to shear, ACI Joumal, Proceedings V. 83, No. 2, pp. 219-231, MarchApr. 1986.

13)MacGregor, J.P.: Reinforced Concrete - Mechanics and Design, Prentice-Hall Inc., Englewood Cliffs, New Jersey, 1988

14)Nielsen, M.P.: Limit analysis and concrete plasticity, Prentice-Hall Inc., Englewood Cliffs, New Jersey, 1984.

15)Wang, W., Jiang, D. H., and Hsu, T. T. C.: Shear strength of reinforced concrete deep beams, J. Struct. Enger., ASCE, V. 119, No. 8, pp.2294-2312, Aug. 1993

16)Marti, P.: Basic tools of reinforced concrete beam design, ACI Joumal, Proceedings V.82, No. 4, pp. 46-56, JanuaryFebruary 1985.

17)Khaled, A. Al-Nahlawi, and James, K. W.: Beam analysis using concrete tensile strength in truss models, $A C I$ Structural Journal, V. 89 , No. 3, pp. 284-289, May-June 1992.

18)Smith, K. N., and Vantsiotis, A.S.: Shear strength of deep beams, ACI Journal, Proceedings V. 79, No. 3, pp. 201-213, 
May-June 1982.

19)Walraven, J., and Lehwalter, N.: Size effects in short beams loaded in shear, ACI structural Journal, V. 91, No. 5, pp. 585-593, Sep.-Oct. 1994.

20)Furuuchi, H., Kodama, T., and Kakuta, Y.: Shear reinforcement in reinforced concrete deep beams, Proceedings of JCI, V. 11, No. 2, pp. 333-338, 1989 (in Japanese).

21)Hayashigawa, T., Saitoh, F., and Kakuta, Y.: Strength of reinforced concrete deep beams with shear reinforcement, Proceedings of $J C I$, V. 12, No. 2, pp.319-324, 1990(in Japanese).

22)Ishibashi, T., Saitoh, K., and Terada, T: Effects of shear reinforcement of reinforced concrete beams with smaller shear span-to-depth ratio, Proceedings of JCI, V. 9, No. 2 , pp.311-316, 1987(in Japanese).

23)Mathey, R. G., and Watstein D.: Shear strength of beams without web reinforcement containing deformed bars of different yield strengths, ACI Journal, Proceedings V. 60, No. 2, pp. 183-206, Feb. 1963.

24)Morrow, J., and Viest, I. M.: Shear strength of reinforced concrete frame members without web reinforcement, $A C I$ Journal, Proceedings V. 53, No. 9, pp. 833-869, March 1957.

25)Moody, K. G., Viest, I. M., Elstner, R. C., and Hognestad, E.: Shear strength of reinforced concrete beams, ACI Journal. Proceedings V. 26, No. 4, pp. 317-332, Dec. 1954.

26)Ramakrishnan, V., and Ananthanarayana, Y.: Ultimate strength of deep beams in shear, ACI Joumal, Proceedings V. 65, No. 2, pp. 87-98, Feb. 1968 27)de Paiva, H. A. Rawdon, and Siess, C. P.: Strength and behavior of deep beams in shear, J. Structural Div., Proceedings of ASCE, V. 91, No. ST5, pp. 19-41, Oct. 1965.

28)Manuel, R. F., Slight, B. W., and Suter, G. T.: Deep beam behavior affected by length and shear span variations, $A C I$ Joumal, Proceedings V. 68, No. 12, pp. 954-958, Dec. 1971.

29)Kani, G. N.: The riddle of shear failure and its solutions, $A C I$ Joumal, Proceedings V. 61, No. 4, pp. 441-467, April 1964.

30)Clark, A. P.: Diagonal tension in reinforced concrete beams, ACI Joumal, Proceedings V. 48, No. 2, pp. 145-156, Oct. 1951.

31)Rogowsky, D. M., and MacGregor, J. G.: Tests of reinforced concrete deep beams, ACI Journal, Proceedings V. 83, No. 4, pp. 614-62.3, July-August 1986.

32)Tan, K. H., Kong, F. K., Teng, S., and Guan, L.: Highstrength concrete deep beams with effective span and shear span variations, ACI Structural Journal, V. 92, No. 4, pp. 395-405, July-August 1995.

33)Niwa, J.: Shear failure mechanism of reinforced concrete beams with small shear span-to-depth ratio, Proceedings of The 37th Annual Conference of JSCE, Part 5, pp. 101-102, 1982(in Japanese).

34)Nishikawa, K., Watanabe, T., Nemoto, S., and Sato, T.: A study on the effects of shear reinforcement of reinforced concrete beams with small shear span-to-depth ratio, Proceedings of The 50th Annual Conference of JSCE, Part 5, pp. 956-957, 1995(in Japanese).

(Received March 19, 1997)

\section{ストラットータイモデルによる R Cディープビームの終局強度解析に関する研究

\author{
元 大淵・日野伸一・太田俊昭
}

ストラットータイモデルは, 慣用はり理論が適用ごきないコンクリート構造物に対する設計手法として有 用されている.しかし、ストラットータイモデルによる解析の精度は, コンクリート有効圧縮強度や節点領域 の決定方法によって大きく変わる. 本研究では, 単純支持された RC ディープビームを対象として, せん断補 強筋を有する場合と有しない場合のそれぞれに対して, はりの終局耐力算定のために可能な解析モデルと, これらのモデルの精度を高めるため, 新たな節点モデルや有効圧縮強度の算定式を提案した. さらに, 既往の 実験結果との比較により本解析手法の妥当性を検討した.これらの結果により, 本解析手法はすべての実験 結果を高い精度で推定できることが明らかになった。 